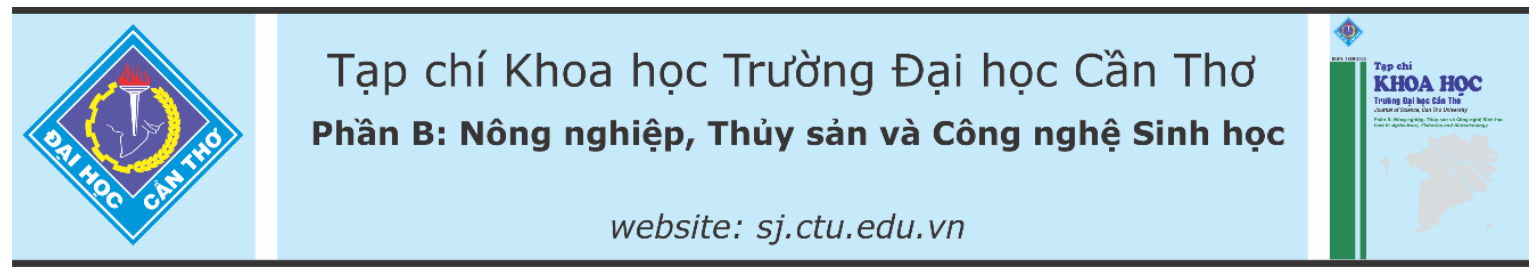

DOI:10.22144/ctu.jvn.2021.044

\title{
NGHIÊN CÚ̉ in vitro CÁC YẾU TỐ ẢNH HƯỞNG ĐẾN SƯ PHÁT TRIỂN CỦA NẦM Alternaria alternata GÂY BỆNH THỐI NGỌN CÀNH TRÊN CÂY THANH LONG (Hylocereus SPP.)
}

\author{
Đỗ Quang Trung ${ }^{1 *}$, Nguyễn Thị Thu Hằng ${ }^{2}$, Phạm Bích Ngọc ${ }^{3}$, Đinh Mai Vân ${ }^{2}$, Trần Thị Hằng ${ }^{2}$ và \\ Lưu Thế Anh ${ }^{1}$ \\ ${ }^{l}$ Viện Tài nguyên và Môi truờng, Đại học Quốc gia Hà Nội \\ ${ }^{2}$ Truờng Đại hoc Lâm nghiệp Việt Nam \\ ${ }^{3}$ Viện Công nghệ sinh hoc, Viện Hàn lâm Khoa hoc và Công nghệ Việt Nam \\ "Nguoòi chị trách nhiệm về bài viết: Đỗ Quang Trung (email: trungcnsinh@gmail.com)
}

\section{Thông tin chung:}

Ngày nhận bài: 02/12/2020

Ngày nhận bài sủa: 09/01/2021

Ngày duyệt đăng: 28/04/2021

Title:

In vitro assay of factors affecting the growth of Alternaria alternata, a casual of stem end rot disease on pitaya (Hylocereus spp.)

\section{Tù khóa:}

Alternaria alternata, độ mặn, kiểm soát sinh hoc, nhiệt độ, $\mathrm{pH}$, thanh long

\section{Keywords:}

Alternaria alternata, salinity, biocontrol, temperature, $p H$, pitaya

\begin{abstract}
Knowing the environment that is unfavorable for the growth of pathogens can be used as basic information to develop appropriate strategies to prevent the occurrence of disease in dragon fruit. In this paper, a number of environmental factors including temperature, $\mathrm{pH}$ and salinity, as well as biological factors including endogenous bacteria species isolated from pitaya showing antagonistic activity on fungi, Alternaria alternata was studied. The growth of A. alternata mycelium is inhibited at $35^{\circ} \mathrm{C}$, while $25^{\circ} \mathrm{C}$ is quite suitable for their growth. The temperature of $30^{\circ} \mathrm{C}$ is favorable for the development of A. alternata. Under different $\mathrm{pH}$ conditions, the growth of A. alternata is most inhibited at $\mathrm{pH} 4$. Moreover, the salinity test results show that A. alternata is not significantly affected by salt concentrations tested. Meanwhile, in vitro testing of antagonistic bacteria showed that both EC120 and EC121 were highly effective in inhibiting the growth of the fungus under investigation. The results of the experiment show that the proper combination of environmental regulation and care regimen can be very beneficial for crop growth in the field as well as the longevity of fruit after harvest.
\end{abstract}

\section{TÓM TẮT}

Biết được môi trương không thuận lợi cho sự phát triển của mầm bệnh có thể được sử dụng làm thông tin co bản để xây dụng các chiến lược thích hợp để ngăn ngừa sự xuất hiện của bệnh trên thanh long. Nghiên cưu nhằm đánh giá một số yếu tố môi trương bao gồm nhiệt độ, độ pH và độ mặn, cũng nhu yếu tố sinh hoc bao gồm các loài vi khuẩn nội sinh phân lập tù cây thanh long đối kháng với nấm gây bệnh, Alternaria alternata. Sư phát triển của sợi nấm A. alternata bi ưc chế ở nhiệt độ $35^{\circ} \mathrm{C}$, trong khi nhiệt độ $25^{\circ} \mathrm{C}$ khá thich hợp cho sụ phát triển của chúng. Nhiệt độ $30^{\circ} \mathrm{C}$ là thuận lợi cho sự phát triển của A. alternata. Trong điều kiện pH khác nhau, sự phát triển của nấm A. alternata hầu hết bi ức chế cực đại ở pH 4. Hon nũa, kết quả thử nghiệm độ mặn cho thấy A. alternata không bị ảnh hưởng nhiều bởi các nồng độ muối được thử nghiệm. Trong khi đó, việc kiểm tra vi khuẩn đối kháng trong ống nghiệm cho kết quả là cả EC120 và EC121 đều có hiệu quả cao trong viẹc ức chế sụ phát triển của loại nấm được khảo sát. Các kết quả thi nghiệm cho thấy sự kết hợp thich hợp của việc điều chỉnh môi trường và chế độ chăm sóc có thể rất hữu ich cho sự phát triển của cây trồng trên đồng ruộng cũng nhu tuổi tho của trái cây sau thu hoạch. 


\section{GIỚI THIÊUU}

Thanh long (Hylocereus spp.) thuộc họ xương rồng và có nguồn gốc từ Nam Mỹ (Crane \& Balerdi, 2005). Ở Việt Nam, phần lớn thanh long được trồng là loài Hylocereus undatus, có đặc điểm vỏ đỏ hay hồng và ruột trắng hoặc ruột đỏ (Nguyễn Như Nhứt và ctv., 2020). Quả thanh long là loại trái cây phổ biến, mang lại nhiều lợi ích cho sức khỏe con người, vì chúng chứa hàm lượng natri, kali và vitamin $\mathrm{A}$ cao; tổng hàm lượng chất rắn lên tới $16,6 \%$ (Tel Zur, 2015). Với ưu thế về điều kiện đất đai khí hậu và kinh nghiệm canh tác của người dân, thanh long đang là một cây trồng chiếm một vị trí quan trọng trong ngành trồng cây ăn quả theo hướng xuất khẩu của Việt Nam.

Tuy nhiên hiện nay, tình hình dịch bệnh trên thanh long đang diễn ra nghiêm trọng, có nhiều bệnh trên cây thanh long đã được ghi nhận từ một số quốc gia sản xuất các loài ruột trắng, đỏ và vàng. Ví dụ như các bệnh do nấm gây ra, chẳng hạn như Alternaria sp., Ascochyta sp., Aspergillus sp., Bipolaris cactivora, Botryosphaeria dothidea, Capnodium sp., Colletotrichum gloeosporioides, Dothiorella sp., Fusarium sp., Gloeosporium agaves, Macssonina agaves, Phytopthora sp. và Sphaceloma sp. (Jin et al., 2020; Le Bellec et al., 2006; Nguyễn Như Nhứt và ctv., 2020; Palmateer et al., 2007; Paull, 2007; Sijam et al., 2008). Trong các bệnh trên cây thanh long, đáng chú ý là bệnh thối ngọn cành do nấm Alternaria sp. gây ra. Bệnh thường xuất hiện quanh năm, đặc biệt vào điều kiện nhiệt độ, độ ẩm cao như vào đầu mùa mưa. Ngọn cành hay đầu cành thanh long bị bệnh sẽ chuyển sang màu vàng, mềm ra sau đó bị thối. Bệnh thối ngọn khiến ngọn cây bị chết, cành không phát triển, ảnh hưởng đến sự phát triển của cây thanh long. Đặc biệt, bệnh xảy ra không những trên đất phèn (đất thấp) mà còn cả trên đất cao.

Kiến thức sinh học cơ bản của mầm bệnh, chẳng hạn như sự liên quan giữa sự nảy mầm và hình thành bào tử với các yếu tố môi trường, sẽ rất hữu ích trong việc phát triển các chiến lược quản lý bệnh bền vững hơn (Xu et al., 2001). Cần phải hiểu chính xác các điều kiện môi trường cho sự lây nhiễm và phát triển của bệnh để xác định thời điểm sử dụng thuốc trừ nấm thích hợp và có thể là thực hiện các biện pháp kiểm soát bệnh thay thế (Percich et al., 1997). Nghiên cứu này đánh giá các yếu tố môi trường cũng như hai vi khuẩn nội sinh (VKNS) đối kháng (EC120 và $\mathrm{EC121})$ với nấm gây bệnh thối ngọn cành (Alternaria alternata) đã phân lập được trên cây thanh long trong điều kiện in vitro.

\section{PHƯONG PHÁP NGHIÊN CÚU}

Các thí nghiệm được thực hiện tại Phòng thí nghiệm Vi sinh, Viện Tài nguyên và Môi trường, Đại học Quốc gia Hà Nội. Các chủng VKNS đồi kháng phân lập từ cây thanh long (EC120 và $\mathrm{EC} 121)$ và mẫu nấm gây bệnh thối ngọn cành sử dụng trong thí nghiệm này được lấy từ bộ sưu tập các chủng vi sinh vật của Phòng thí nghiệm Vi sinh. Một số yếu tố môi trường bao gồm nhiệt độ, $\mathrm{pH}$ và độ mặn và các chủng VKNS đối kháng chống lại các loại nấm gây bệnh đó đã được nghiên cứu.

\section{1. Ảnh hưởng của nhiệt độ}

Chủng nấm nghiên cứu được nuôi cấy trên đĩa có chứa môi trường PDA và sau đó được ủ ở 4 nhiệt độ khác nhau là $20,25,30$, hoặc $35^{\circ} \mathrm{C}$ trong 10 ngày theo phương pháp được phát triển bởi Baird (2004). Sự phát triển của nấm được theo dõi bằng cách đo đường kính sợi nấm bằng thước đo (Digimatic Calibre, Japan) hai ngày một lần. Các thí nghiệm được lặp lại ba lần.

\section{2. Ảnh hưởng của pH}

Chủng nấm nghiên cứu được nuôi cấy trên môi trường PDA. Giá trị $\mathrm{pH}$ đã được điều chỉnh thành 4 ; 5,5; 7; 8,5 hoặc 10 (Fayzalla et al.., 2008). pH được xác định bằng máy đo $\mathrm{pH}$ Delta 320 (Mettler, Toledo). Sự phát triển của nấm được theo dõi bằng cách đo đường kính sợi nấm bằng thước cặp kỹ thuật số hai ngày một lần. Các thí nghiệm được lặp lại ba lần.

\section{3. Ảnh hưởng của độ mặn}

Các chủng nấm phân lập được nuôi cấy trên đĩa PDA trong 10 ngày với năm nồng độ độ muối $\mathrm{NaCl}$ khác nhau $\left(0,1,10,100,1.000 \mathrm{mg} \mathrm{L}^{-1}\right)$ (Al-Rokibah et al., 1998). Sự phát triển của nấm được theo dõi bằng cách đo đường kính sợi nấm bằng thước cặp kỹ thuật số hai ngày một lần. Các thí nghiệm được lặp lại ba lần.

\section{4. Ảnh hưởng của vi khuẩn nội sinh đối kháng}

Thí nghiệm này được thực hiện với quy trình nuôi cấy kép theo phương pháp do Sijam and Dikin (2005) phát triển bằng cách nuôi cấy cả nấm phân lập và vi khuẩn đối kháng trong đĩa PDA trong 10 ngày ở nhiệt độ phòng. VKNS đối kháng, $\mathrm{EC} 120$ và EC121, được nuôi cấy trên LB (Oxoid Ltd., Basingtoke, Hampshire, Anh) từ bộ sưu tập của Phòng thí nghiệm vi sinh, Viện Tài nguyên và Môi trường, Đại học Quốc gia Hà Nội. Mẫu nấm (đường kính $4 \mathrm{~mm}$ ) được đặt cách mép đĩa cấy $2 \mathrm{~cm}$; trong khi VKNS đối kháng cấy ở phía đối diện trên cùng 
một đĩa. Sự phát triển của nấm được theo dõi bằng cách đo cả hướng tâm của sợi nấm về phía rìa đĩa (được coi là Ro) và về phía VKNS (được coi là Rt) bằng thước cặp kỹ thuật số 2 ngày một lần. Các thí nghiệm được lặp lại ba lần. Sự ức chế của VKNS đổi kháng chống lại các chủng nấm được phân lập theo công thức sau:

$$
\mathrm{H}=(\mathrm{Ro}-\mathrm{Rt}) / \operatorname{Ro} \mathrm{x} 100
$$

Trong đó, H: Hiệu quả ức chế (\%); Ro = Sự phát triển của sợi nấm về phía mép đĩa $(\mathrm{mm}) ; \mathrm{Rt}=\mathrm{Sự}$ phát triển của sợi nấm về phía vi khuẩn $(\mathrm{mm})$.

\subsection{Phân tích thống kê}

Các số liệu thí nghiệm được đánh giá bằng các phương pháp thống kê phân tích biến thiên (Analysis of Variance, ANOVA), so sánh trung bình theo phép thử Duncan. Các số liệu ghi nhận được xử lí bằng Excel và phần mềm SPSS phiên bản 19 .

\section{KÊT QUẢ VÀ THẢO LUẬN}

\section{1. Ảnh hưởng của nhiệt độ}

Nhìn chung, kết quả thí nghiệm xử lý nhiệt độ cho thấy sự phát triển liên tục của sợi nấm bị ức chể ở nhiệt độ 30 và $35^{\circ} \mathrm{C}$; trong khi nhiệt độ $20^{\circ} \mathrm{C}$ khá thích hợp cho sự phát triển của chúng. Nhiệt độ $25^{\circ} \mathrm{C}$ thuận lợi cho sự phát triển của A. alternata (Hình 1).

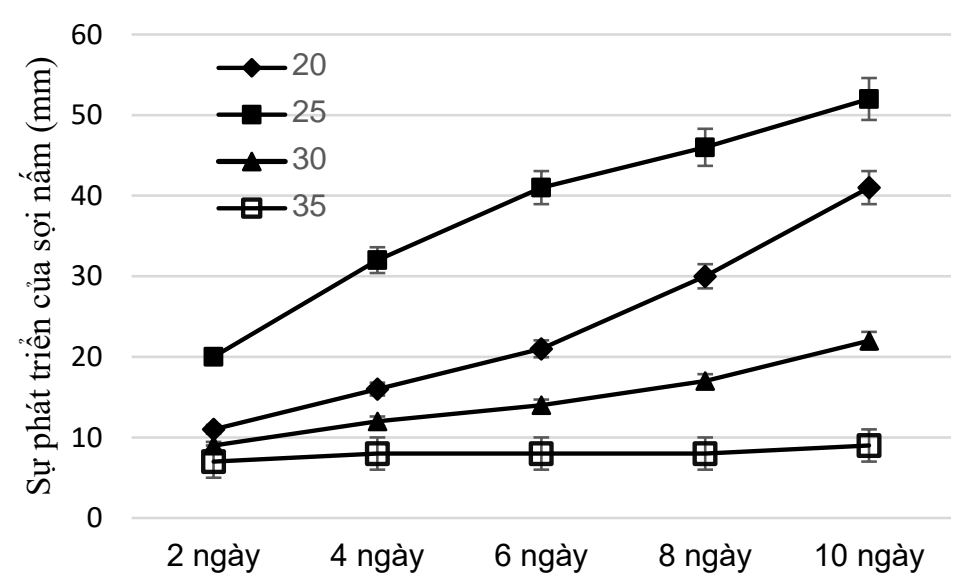

Hình 1. Ảnh hưởng của nhiệt độ đến sự phát triển của nấm A. alternata trong điều kiện in vitro

\section{2. Ảnh hưởng của pH}

Thí nghiệm in vitro về ảnh hưởng của $\mathrm{pH}$ nói chung cho thấy sự phát triển của nấm $A$. alternata bị ức chế bởi $\mathrm{pH} 4$. Sự ức chế do $\mathrm{pH} 4$ có hiệu quả cho đến thời điểm kết thúc thí nghiệm. Kết quả thí nghiệm cho thấy giá trị pH trong khoảng 5,5-10 ít ảnh hưởng hơn tới sự phát triển của nấm $A$. alternata và $\mathrm{pH} 7$ là lý tưởng và tạo ra sự phát triển sợi nấm trung bình tối đa (Hình 2).

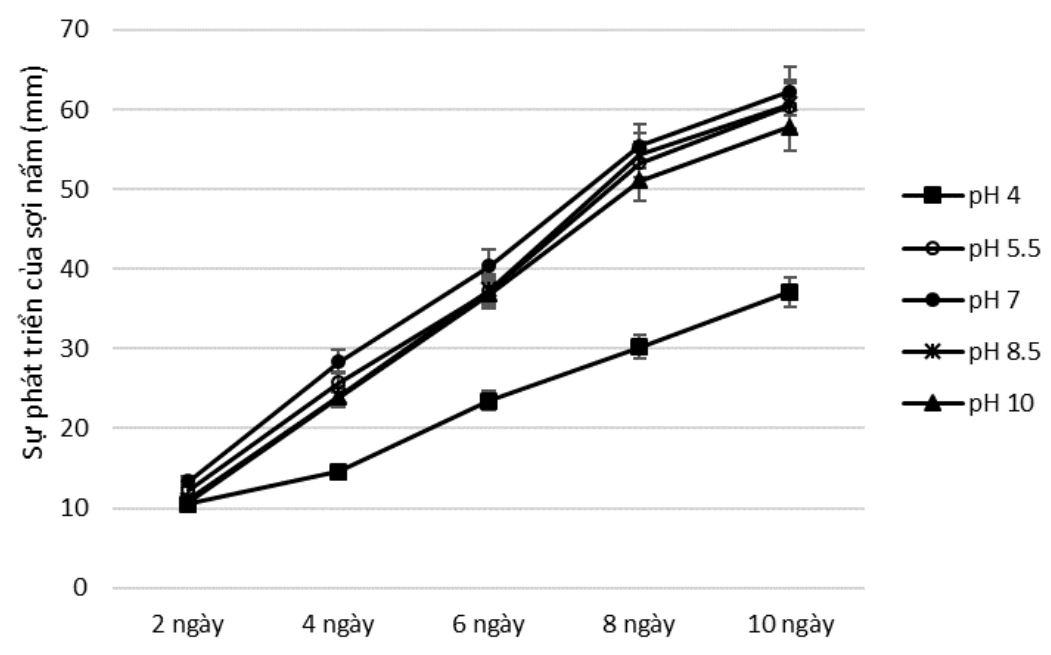

Hình 2. Ảnh hưởng của pH đến sự phát triển của nấm $A$. alternata trong điều kiện in vitro 


\section{3. Ảnh hưởng của độ mặn}

Các kết quả thí nghiệm về sự kháng mặn cho thấy các nồng độ mặn khác nhau đều có những tác động khác biệt đáng kể đối với A. alternata so với đối chứng (Hình 3).

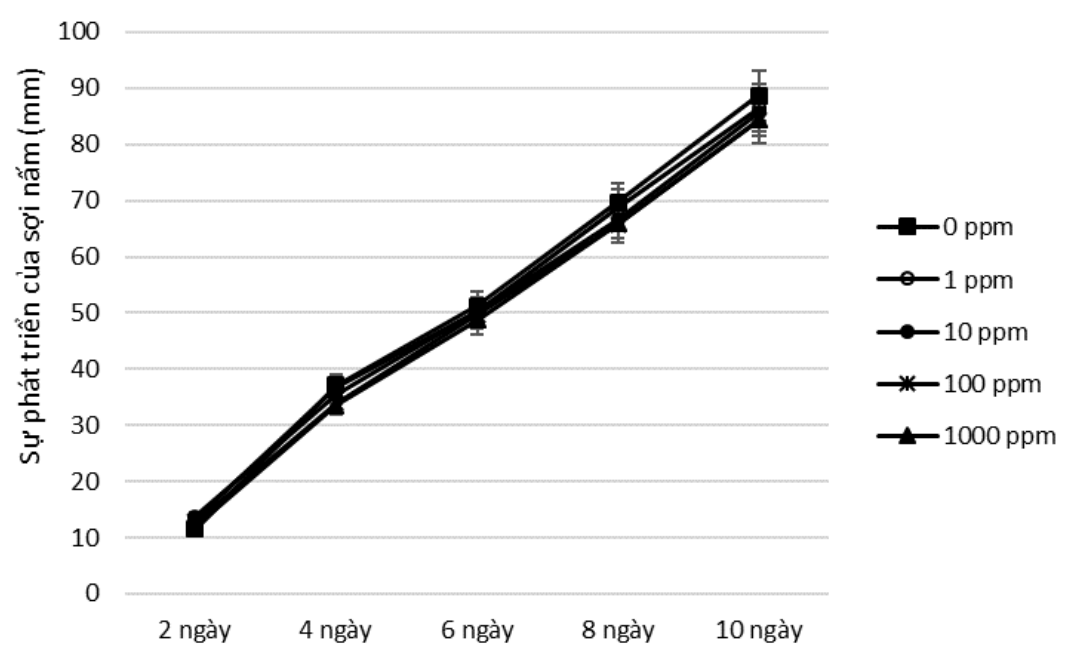

Hình 3. Ảnh hưởng của nồng độ muối $\mathrm{NaCl}$ đến sự phát triển của nấm A. alternata trong điều kiện in vitro

\section{4. Ảnh hưởng của VKNS đối kháng}

Kết quả kiểm tra VKNS đối kháng cho thấy cả EC120 và EC121 có hiệu quả cao trong việc ức chế sự phát triển của nấm A. alternata (Hình 4). Trong
6 ngày đầu tiên khả năng ức chế của hai chủng đạt $60 \%$. Trong các ngày tiếp theo khả năng ức chể của các chủng VKNS này ồn định và dao động trong khoảng 60-63\%.

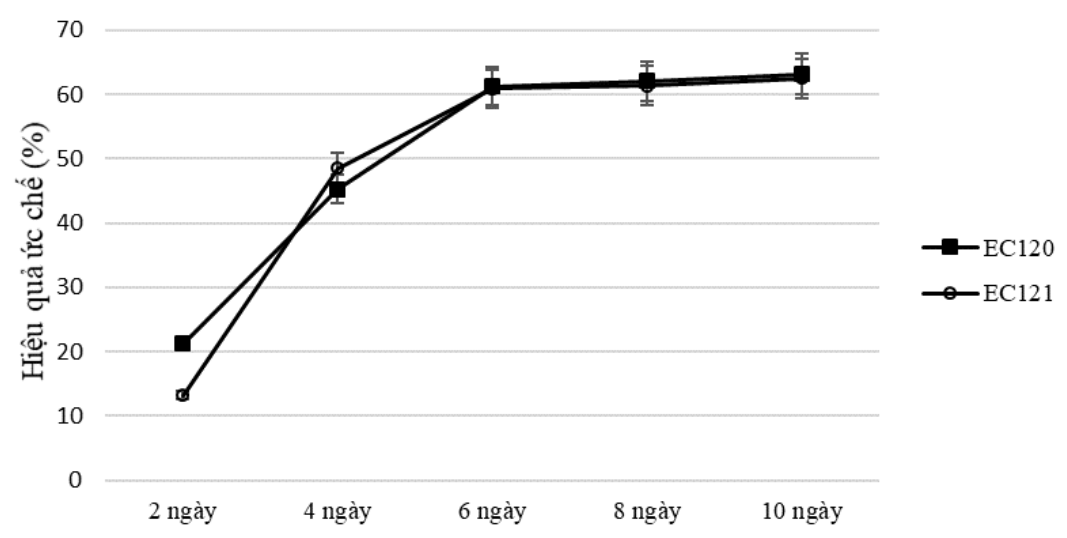

Hình 4. Ảnh hưởng của vi khuẩn nội sinh đối kháng đến sự phát triển của nấm $A$. alternata trong điều kiện in vitro

\section{THẢO LUẬN}

Nhìn chung, sự phát triển của nấm gây bệnh thối nhũn A. alternata bị ức chế đáng kể bởi mức độ cực đoan (tối thiểu và tối đa) của các nghiệm thức, ngoại trừ xử lý bằng độ mặn. Trong khi đó, hai loại VKNS đối kháng được sử dụng có thể hạn chế sự phát triển sợi nấm của mầm bệnh. Tuy nhiên, những phát hiện này không giống như những phát hiện trên các loài nấm khác nhau trên các cây trồng khác nhau. Tỷ lệ nảy mầm tối đa của nấm Bipolaris sorokiniana gây ra phức hợp bệnh trên cây Poa pratensis và Agrostis palustris là lớn nhất ở 25 và $30^{\circ} \mathrm{C}$, nhưng nó không nảy mầm ở $35^{\circ} \mathrm{C}$ (Hodges, 1975); trong khi Barba et al. (2002) quan sát thấy sự hình thành bào tử của $B$. sorokiniana trên hạt lúa mạch đạt cực đại ở $19,3^{\circ} \mathrm{C}$.

Nấm thường chỉ sử dụng cơ chất ở dạng dung dịch để tạo ra các chất cần thiết cho sự phát triển và sự trao đổi chất của chúng. Do đó, $\mathrm{pH}$ có vai trò quan 
trọng trong quá trình phát triển của sợi nấm. Kết quả thí nghiệm chỉ ra rằng sự phát triển sợi nấm $A$. alternata thích hợp khoảng $\mathrm{pH}$ từ 7 đến 10 . Môi trường $\mathrm{pH}$ kiềm cho A. alternata phù hợp với các nghiên cứu khác trước đó (Gawai \& Mangnalikar, 201-8). Bischoff and Garraway (1987) giả định rằng sự tích tụ ammonium và tăng độ $\mathrm{pH}$ trên môi trường rắn có thể làm tăng sản xuất NADP-glutamate dehydrogenase và NAD-glutamate dehydrogenase trong nuôi cấy lỏng nấm Bipolaris maydis có liên quan đến sự hiện diện của sợi nấm và của sợi nấm với bào tử.

Sự ức chế không đáng kể của các mức độ mặn nhất định đối với sự phát triển của nấm $A$. alternata trong nghiên cứu này phù hợp với một số kết quả thu được từ các nghiên cứu trước đó. Thí nghiệm in vitro do Hopkins and McQuilken (2000) cho thấy nấm Pestalotiopsis sydowiana (tác nhân gây bệnh trên lá, gốc và rễ trên cây cảnh tại các vườn ươm thương mại ở Anh) có tỷ lệ mở rộng sợi nấm nhanh nhất khi được nuôi trên PDA có bồ sung muối $\mathrm{NaCl}$. Trong một nghiên cứu khác về ảnh hưởng của độ mặn đến sự phát triển của sợi nấm thì dung dịch muối (nồng độ 0,1 và $0,2 \mathrm{M}$ ) đã làm tăng cường sự phát triển của bệnh thối rễ trên cây Cúc (do nấm Phytophthora cryptogea gây ra) lên tương ứng là 70 và $88 \%$ (MacDonald, 1982).

Tuy nhiên, những phát hiện của nghiên cứu này có sự sai khác với một số công trình nghiên cứu vai trò của muối $\mathrm{NaCl}$ trong việc ngăn chặn bệnh thối ngọn và thối rễ trên cây măng tây (Asparagus officinalis L.) do $F$. oxysporum hoặc $F$. proliferatum gây ra (Elmer, 2003). Trong báo cáo đó, tác giả đã công bố mức độ giảm các vết thương ở rễ tiếp xúc trực tiếp với $\mathrm{NaCl}$ (giảm 51\%) cao hơn đáng kể so với rễ không tiếp xúc (giảm 31\%).

Mặt khác, thí nghiệm in vitro này đã chứng minh rằng cả $\mathrm{EC} 120$ và $\mathrm{EC} 121$ có thể là tác nhân kiểm soát sinh học nấm $A$. alternata. Kết quả này phù hợp với một số báo cáo trước đây về khả năng tạo ra chât kháng nấm của các chủng vi khuẩn (Dikin et al., 2007; Luu et al., 2021). Ví dụ như Dikin et al. (2007) báo cáo rằng các chất kháng khuẩn của vi khuẩn $B$. multivorans có thể hạn chể sự phát triển của nấm Schizophyllum commune, tác nhân gây bệnh của mầm nâu và bệnh thối hạt trên cọ dầu.

\section{KẾT LUẬN}

Sự phát triển của sợi nấm được thử nghiệm bị ảnh hưởng nhiều bởi điều kiện nhiệt độ khắc nghiệt $\left(35^{\circ} \mathrm{C}\right)$ và $\mathrm{pH}(\mathrm{pH} 4,0)$. Các nồng độ muối có thể ức chế đáng kể đến sự phát triển của nấm $A$. alternata; trong khi các vi khuẩn nội sinh đối kháng được sử dụng, chủng EC120 và EC121, có hiệu quả nhất trong việc hạn chế sự phát triển của nấm thử nghiệm trong điều kiện in vitro. Các kết quả thí nghiệm cho thấy sự tương quan thuận nghịch giữa sự cải biến môi trường một cách hợp lý và sự phát triển của cây trồng trên đồng ruộng cũng như tuồi thọ của trái cây sau thu hoạch.

\section{LÒ̀I CẢM ƠN}

Xin cảm ơn Học viện Khoa học và Công nghệ, Viện Hàn lâm Khoa học và Công nghệ Việt Nam đã hỗ trợ kinh phí cho nghiên cứu này dưới hình thức học bổng sau tiến sĩ (Mã số GUST.STS.ĐT2020SH05).

\section{TÀI LIỆU THAM KHẢO}

Al-Rokibah, A.A., Abdalla, M.Y., \& El-Fakharani, Y.M. (1998). Effect of water salinity on Thielaviopsis paradoxa and growth of date palm seedlings. J. King Saud Univ. Agric. Sci., $10,55-63$.

Baird, R.E. (2004). Laboratory Exercises Illustrating Some Fungi in Deuteromycota. In: Plant Pathology, Concepts and Laboratory Exercises, Trigiano, R.N., Windham M.T. \& Windham A.S. (Eds.). CRC Press, New York, pp. 141-149.

Barba, J.T., Reis E.M., \& Forcelini, C.A. (2002). Effect of temperature and fungicide on the transmission of Bipolaris sorokiniana from seeds to barley plants. Fitopatol. Brasileira, 27, 500-507.

Bischoff, T.W., \& Garraway, M.O. (1987). Effects of glycose on NADP and NAD glutamate dehydrogenase activities and their relation to ammonium and $\mathrm{pH}$ levels in cultures of Bipolaris maydis race T. Mycopathologia, 98, 141-148.

Crane, J.H. \& Balerdi, C.F. (2005). Pitaya growing in the Florida home landscape. IFAS Extension. HS1068, 1-9.

Dikin, A., Sijam, K., Kadir, J., \& Seman, I.A. (2007). Mode of action of antimicrobial substances from Burkholderia multivorans and Microbacterium testaceum against Schizophyllum commune Fr. Int. J. Agric. Biol, 9, 311-314.

Elmer, W.H. (2003). Local and systemic effects of $\mathrm{NaCl}$ on root composition, Rhizobacteria and Fusarium crown and root rot of Asparagus. Phyopathology, 93, 186-192.

Fayzalla, E.S.A., Shabana, Y.M., \& Mahmoud, N.S. (2008). Effect of environmental conditions on wilting and root rot fungi pathogenic to solanaceous plants. Plant Pathol. J, 7, 27-33. 
Gawai, D.U., \& Mangnalikar, S.S. (2018). Effect of Temperature and $\mathrm{pH}$ on growth of Alternaria alternata, leaf spot pathogen of soyabean. Bioscience Discovery, 9(1), 162-165.

Hodges, C.F. (1975). Comparative total and proportional rate of germination of Bipolaris sorokiniana and Curvularia geniculata conidia is influenced by culture age and temperature. Mycopathologia, 57, 9-14.

Hopkins, K.E., \& McQuilken, M.P. (2000). Characteristics of Pestalotiopsis associated with hardy ornamental plants in the UK. Eur. J. Plant Pathol., 106, 77-85.

Jin, X.L., Ko, Y.Z., Siti Nordahliawate, M.S., Mohd, M.H., \& Chiang, Y.C. (2020). First report of stem canker of dragon fruit caused by Alternaria spp. in Taiwan. New Disease Reports, 41, 35.

Le Bellec, F., Vaillant, F., \& Imbert, E. (2006). Pitahaya (Hylocereus spp.): A new fruit crop, a market with a future. Fruits, 61, 237-250.

Luu, T.A., Phi, Q.T., Nguyen, T.T.H., Dinh, M.V., Pham, B.N. \& Do, Q.T. (2021). Antagonistic activity of endophytic bacteria isolated from weed plant against stem end rot pathogen of pitaya in Vietnam. Egyptian journal of pest biocontrol, 31(14), 1-8.

MacDonald, J.D. (1982). Effect of salinity stress on the development of Phytophthora root rot of Chrysanthemum. Phyopathology, 72, 214-219.

Nguyễn Như Nhứt, Nguyễn Thị Ngọc Bích, Nguyễn Thanh Trường, Võ Thị Xuyến (2019). Phân lập nấm bệnh Neoscytalidium dimidiatum trên cây Thanh long và nghiên cứu kiểm soát bằng vi sinh vật. Sci. Tech. Dev. J. - Nat. Sci., 3(4), 286-293.
Percich, J.A., Nyvall R.F., Malvick D.K., \& Kohls C.L. (1997). Interaction of temperature and moisture on infection of wild rice by Bipolaris oryzae in the growth chamber. Plant Dis., 81, 1193-1195.

Palmateer, A.J., Ploetz, R.C., Van Santen, E., \&Correll, J.C. (2007). First report of anthracnose caused by Colletotrichum gloeosporioides on Pitaya. Plant Dis., 91, 631-631.

Paull, R.E. (2007). Dragon Fruit. Department of Tropical Plant and Soil Sciences University of Hawaii, Manoa, Honolulu.

Sijam, K., \& Dikin, A. (2005). Biochemical and physiological characterization of Burkholderia cepacia as biological control agent. Int. J. Agric. Biol., 7, 385-388.

Sijam, K., Awang, Y., \& Satar, M.G.M. (2008). Fungi associated with diseases on dragon fruit (Hylocereus spp.) in Peninsular Malaysia. Proceedings of the Microbes: Biotechnology Engine for Health and Wealth Creation. Hyatt Regency Resort, Kuantan, Pahang Darul Makmur, Malaysia, Aug. 16-19, Malaysian Society for Microbiology, pp. 234-237.

Tel Zur, N. (2015). Research and development of pitahayas - dragonfruit - vine cacti: limitations and challenges and the current global market. Acta Hortic. (Wagening.), 1067, 365-370.

Xu, X.M., Guerin, L., \& Robinson, J.D. (2001). Effects of temperature and relative humidity on conidial germination and viability, colonization and sporulation of Monilinia fructigena. Plant Pathol., 50, 561-568. 